INFORMATION SYSTEMS FOR REGIONAL DEVELOPMENT

PLANNING: A STATE-OF-THE-ART SURVEY

Peter Nijkamp

Department of Economics, Free University, Amsterdam, The Netherlands

RR-84-7

March 1984

Reprinted from Environment and Planning B: Planning and Design, volume 10 (1983)

INTERNATIONAL INSTITUTE FOR APPLIED SYSTEMS ANALYSIS

Laxenburg, Austria 
Research Reports, which record research conducted at IIASA, are independently reviewed before publication. However, the views and opinions they express are not necessarily those of the Institute or the National Member Organizations that support it.

Reprinted with permission from Environment and Planning B: Planning and Design, 10(3):283-302. Copyright (c) 1983 Pion Limited.

All rights reserved. No part of this publication may be reproduced or transmitted in any form or by any means, electronic or mechanical, including photocopy, recording, or any information storage or retrieval system, without permission in writing from the copyright holder.

Printed by Novographic, Vienna, Austria 


\section{FOREWORD}

IIASA's research on regional issues has, for a number of years, made use of regional case studies in four member countries as a vehicle for identifying universal problems in regional development, the corresponding planning activities, and the process of regional policy formation. A recent study on "Information Systems for Integrated Regional Planning" is an offspring of the regional research program. It is founded on a broad assessment and comparison of the design and utilization of regional information systems across a group of countries with different institutional settings and planning traditions. In particular, this work aims at characterizing a general unifying methodology for integrated information systems as well as pointing out new directions and developments in information systems technology and design. In the present report, Peter Nijkamp summarizes the results of the study and provides a state-of-the-art review.

BÖRJE JOHANSSON

Acting Leader

Regional Issues Project 



\title{
Information systems for regional development planning: a state-of-the-art survey
}

\author{
P Nijkamp q \\ Department of Economics, Free University, PO Box 7161, 1007 MC, Amsterdam, The Netherlands \\ Received 4 July 1983; in revised form 21 October 1983
}

\begin{abstract}
In this paper the author presents a state-of-the-art review of information systems for regional development planning. Various aspects and tools of such information systems are discussed. Next, an international comparison of spatial planning-systems and spatial information-systems in six countries is made by means of a systematic inventory and typology of attributes of these information systems. The author concludes that regional information-systems are in general not very well developed and suggests various ways for improving the current situation.
\end{abstract}

\section{Information systems: an introduction}

In the postwar period many countries have experienced an information explosion. The introduction of computers, microelectronic equipment, and telecommunication services has paved the way for an avalanche of information, not only for scientific research, but also for providing insight to a broader public and for planning or for policy purposes (see also Burch et al, 1979). Several reasons may explain this information explosion in planning and policymaking (see Nijkamp and Rietveld, 1984):

Our complex society needs insight into the mechanisms and structures determining intertwined socioeconomic, spatial, and environmental processes.

The high risks and costs of wrong decisions require a careful judgement of the impact of all alternative courses of action.

Public policy agencies exhibit complex and conflicting interests, so that the availability of information itself is an essential part of policy strategies ('information is power').

The scientific progress in statistical, technical, and econometric modeling has led to a clear need for more adequate data and information monitoring.

Modern computer software and hardware facilities (for example, decision support systems) have provided the conditions for a quick and flexible treatment both of hard and of soft data regarding all aspects of policy analysis.

Many statistical offices have produced a great deal of data which can be usefully included in appropriate information-systems.

It should be noted that there is an essential difference between data and information. Data are numerical representations or other symbolic surrogates aiming at characterizing attributes of people, organizations, objects, events, or concepts. Information means data which are structured (by way of modeling, organizing, or converting) so as to increase the insight or level of knowledge regarding a certain phenomenon. Thus, an information system is based on a systematic data transformation which aims at providing analytical support to planners and decisionmakers (compare Rittel, 1982). Restructuring and transformation of data are thus essential in information systems. Various operations on data that may be carried out are: capturing, verifying, classifying, arranging, summarizing, calculating, forecasting, simulating, storing, retrieving, and communicating. The costs of such operations depend inter alia on the personnel requirement, the modularity, flexibility, and versatility of the system concerned, and on the processing speed and control. The benefits are determined

I This article was written during a stay at IIASA, Laxenburg A-2361, Austria. 
inter alia by the accessibility, comprehensiveness, accuracy, appropriateness, timeliness, clarity, flexibility, verifiability, freedom from bias, and quantifiability of the information needed.

Information systems are important vehicles for the paradigm of rational decisionmaking. They provide the necessary ingredients for an ex ante and an ex post justification of choices to be made (compare Faludi, 1973). In this regard, information systems are not only relevant at the level of microdecision units (in firms, for example), but also at the macrolevel of social, economic, and political organizations (see Sowell, 1980). Not only in the developed countries, but also in developing countries, proper and systematic information is a necessary condition for successful planning (compare also Casley and Lury, 1981; Chatterjee and Nijkamp, 1983).

In the present paper, I aim at providing a reflection on information systems for public planning, especially in an urban and regional context. The relevance of this endeavour can be based on the following arguments:

Information systems may-in a multifaceted planning system-provide an integrative framework for multidisciplinary analysis, based on an interaction between such different disciplines as geography, planning, economics, demography, regional science, architecture, and public management.

Information systems based on empirical data contribute to an operational analysis of planning issues in complex dynamic systems.

Information systems are helpful in specifying and identifying the essential characteristics (trade-offs, conflicts) of real-world policy or choice problems.

A great deal of entirely new possibilities in the area of data storage and of data treatment have come up, so that information systems may act as an operational vehicle for identifying systematic patterns in a complex, evolving, and multifaceted world.

Information systems are a prerequisite for building, testing, and using empirical models for policy analysis (compare Leontief, 1982).

Information systems may provide a unifying framework for judging different, sometimes conflicting, options in a planning system characterized by various interest groups and decision agencies.

In conclusion, information plays a key role in all planning and decision activities, as it is one of the integrating forces behind planning and management. The provision of reliable, manageable and up-to-date information-structured in a logical way on the basis of a sound methodology-is essential for understanding and actively influencing technological, socioeconomic, spatial, and environmental processes in a rational and systematic way. Information systems provide the necessary insight into elements, components, properties, linkages, and dynamics of such processes. However, the geographical dimensions of these developments have not yet adequately been addressed in information systems for public planning and decisionmaking. These issues will be discussed in greater detail in subsequent sections of this article.

It should be noted that the provision of logically and systematically organized data may lead either to an increase or to a decrease in the initial level of knowledge about a phenomenon. The latter case is sometimes called 'misinformation': it leads to a removal of unjustified prior certainty a decisionmaker may have regarding the expected outcomes of his decisions. In this regard, Rittel (1982) states that information generated in a planning context may have an impact on various types of knowledge of planners and decisionmakers: conceptual, factual, deontic, explanatory, and instrumental.

A specific kind of misinformation may emerge if a decisionmaker purposely creates uncertainty, inter alia by a selective use of information or by a dissemination of 
mutually contradictory statements. By inducing more confusion on real-world developments, a decisionmaker may achieve an expansion of his own decision space. Such strategic uncertainty may be generated if, for instance, a decisionmaker is purposely advocating the use of two mutually contradictory models (or other competing information-systems) for conflicting planning issues.

In general, information may also be interpreted by means of the principle of surprise. A message about an event contains more information as the discrepancy between prior (expected) results and posterior (realized) effects is higher. In this way, Shannon and Weaver's classic measure from information theory may be used to judge the relevance of information systems for decisionmaking: more information reduces the entropy of a system ('negentropy'). Last, it should be noted that an information system may also be useful for identifying the minimum requirements for taking a deliberate decision. If the information level is too low to warrant a decision, it may be more appropriate to postpone a decision in order to collect more specific reliable data, unless the costs of a delay would be higher than the expected benefits of gathering more reliable information. This so-called principle of trichotomous segmentation is extensively discussed by Roy (1981). In this case, information systems may indicate the margins within which choices may be justified on rational and scientific grounds.

\section{Elements of information systems}

Information systems constitute the empirical foundation for policy analysis.

Phenomena in policy analysis can be described in various ways, for instance, by means of theoretical constructs or by means of operational concepts. In the phase of theorizing on problems to be analyzed, the theoretical constructs are often called latent variables, but in the phase of hypothesis testing, empirical analysis, model building, or planning, one needs observable facts. Such operational variables are then usually proxy measures for the relevant variables. It should be noticed that even operational and measurable variables may pose validity problems, as they have to be adjusted to specific analytical issues. For instance, if one wants to assess the impact of urban infrastructure on urban value added, the variable measuring urban infrastructure has to be defined and standardized in a meaningful way; for instance, by relating it to the actual use of infrastructure, the number of inhabitants, or the urban activity density.

In an ideal situation, each information system should be designed for specific planning purposes, but in reality one very often has to use an existing and given data base. For instance, the results of an international survey of multiregional models showed that the majority of these models did not develop their own specific data base, but employed mainly the existing data provided by various statistical offices (see Issaev et al, 1982).

Observable data can be measured on different scales, namely a metric and a nonmetric scale. The metric scale includes the interval and ratio scale, whereas the nonmetric scale includes the nominal and ordinal scales. In addition, fuzzy set analysis has also become more important in data analysis and planning. In recent years enormous progress in the area of nonmetric data analysis has taken place (see Nijkamp, Leitner, and Wrigley, 1984). In various research fields (for instance, transportation, housing, migration), modern analytical tools from nonmetric data analysis are increasingly being used (for instance, disaggregate choice models, generalized log-linear models for categorical data). This research direction has convincingly demonstrated that elements of information systems need not necessarily be cardinal in nature: qualitative data (for example, ordinal performance measures) may also provide meaningful information for planning. Even linguistic statements 
(for instance, those emerging from a fuzzy set context) may be used in modern information and computer-consulting systems. The increasingly important role of decision support systems (see also later) is another indication of the potential of modern computer systems to deal with qualitative information in complex choice situations.

It should be added that one is usually interested not only in measures describing the state of a system, but also (and often especially) its evolution. In this respect, recently developed monitoring and retrieval systems may be extremely useful vehicles. According to the Commission on Geographical Data Sensing and Processing of the International Geographical Union (1980) an ideal information system in a spatial context is made up of six major subsystems:

1 management subsystem;

2 data acquisition subsystem;

3 data input and storage subsystem;

4 data retrieval and analysis subsystem;

5 information output subsystem;

6 information use subsystem.

All these subsystems indicate that information plays a role in all stages of planning activities. Altogether, these systems may be used for the following purposes:

description as a structural representation of data regarding a system (by means of multidimensional profiles, for example);

impact analysis as a method for assessing the foreseeable and expected consequences of certain courses of action (on the basis of a model or simulation experiments, for example);

evaluation as a way of judging the relative merits of different alternative choices (on the basis of multiple criteria analysis, for example).

In many situations, there is a conflict between generality and specificity of information systems. Generality refers to the design of information systems, based on coherence and versatility. Clearly, in general, specific information-systems are easier to handle and less expensive, but they may have an ad hoc and incoherent nature and may not always be available when they are needed.

Between these two extremes, a new stream of information systems has emerged in recent years, namely adaptive information-systems. Such systems are based on a procedural view of planning and policymaking, so that a certain problem orientation with regard to a specific planning issue is placed in a long-term and coherent perspective, taking into account interactions between decisionmakers, individuals, and interest groups. Furthermore, such adaptive information-systems may also emerge from a systems view of planning, in which feedback effects provide a flexible frame of reference. Last, adaptive information-systems are more open and future-oriented, so that conflict analysis, planning theory, and political science can also be included as cornerstones for such information systems.

\section{Information systems and planning}

A planning-oriented and future-oriented view of information systems may reveal a discrepancy between the field of interest covered in planning and the focus of a given information-system. Especially in case of long-term planning problems this discrepancy may be significant (see figure 1). Information systems play a role in planning, but usually the actual contents of an information system do not cover the long-run issues in a planning context. Contemporary planning issues like energy scarcity and innovation are hardly included in any information system and demonstrate clearly the lack of future orientation of current information-systems. Such questions once more 
illustrate that information systems should not start off from current interests, but should try to encompass new components that are not yet receiving much attention, but may potentially become crucial issues in the future. Examples are: effects of international pollution, conflicting behaviour between different public agencies, regional dimensions of multinational companies, impacts of an industrial reorientation, spatial aspects of the growing importance of agriculture, spatial consequences of microelectronics, etc.

Wilbanks and Lee (1984) mention five bottlenecks precluding a direct and smooth application of information from scientific analysis in policymaking:

1 the lack of tailor-made scientific tools for various policy issues, given the time constraints prevailing in policymaking;

2 the discrepancy between basic scientific research and the needs of planners and politicians;

3 the existence of gaps in our knowledge (for instance, interaction effects across disciplinary boundaries, institutional undertainties, unforeseeable events, etc);

4 the lack of integration in scientific research, leading to a production of piecewise kinds of information;

5 the lack of learning from experiences (especially failures) from the past.

It is evident that user-surveyer communication is necessary for removing these bottlenecks. It is important that the user or client is not disconnected from an information system, but it is equally important that an analyst is informed about the way a certain policy issue or problem is structured. The modern communication technologies no doubt provide an enormous potential, although they cannot replace the contacts between users and analysts. In several choice-situations, however, interactive simulation experiments and computer graphics-designed by experts-can nowadays already directly be used by decisionmakers and planners, so that policy and analysis may be brought closer together in the future. In this respect, adaptive information-systems seem to offer a great potential.

Another problem may emerge from a misunderstanding of information systems: it is often assumed that information systems have mainly a cost nature. In that case, the increase in the level of knowledge would only have to be traded-off against the costs of the information system. This is, however, only a partial view on information systems, as the opportunity costs are not considered: information systems may also have other benefits, as they may lead to avoiding the costs of taking wrong decisions. Thus the value of an information system cannot properly be judged without taking into account and evaluating the costs and benefits of all relevant courses of action.

There is, however, a problem involved in judging the outcomes of all actions, as there is usually no common denominator for all outcomes of the alternative courses of action. Traditional evaluation methods (such as cost-benefit analysis) have failed to incorporate intangible effects, so that no integrated evaluation could take place. In this respect, the modern multiple criteria methods and multiple objective decision methods are much more promising, as these methods provide a sound and operational methodology for a coherent and integrated assessment of multifaceted impacts of all

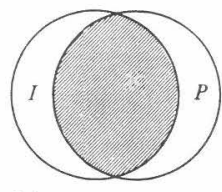

(a)

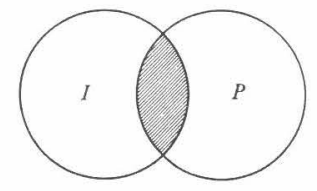

(b)

Figure 1. Overlap of planning fields, $P$, and information systems, $I$ (a) in the short term, (b) in the long term. 
courses of action [for surveys see among others, Nijkamp $(1979 ; 1980)$ and Voogd (1983a; 1983b)].

This problem of incommensurable decision-criteria also has a positive aspect, because it increases the need for communication between a decisionmaker and an analyst, especially if there is lack of information regarding political weights. In such cases, interactive strategies between a decisionmaker and an analyst may be effective tools for reaching a compromise between conflicting decision-criteria. Such an interactive procedure is normally based on a dialogue between the analyst and the user, but in this context a computer may serve to make the necessary quick calculations. In recent years, such interactive multidimensional choice analyses have demonstrated their potential on many occasions, in the area both of private and of public planning (see also Spronk, 1981). In combination with the use of a computer, they are important vehicles for employing information systems in a user-expert communication and may also play an important role in adaptive information-systems.

As mentioned before, removal of uncertainty and risk are basic elements in information systems. In this regard, the relationship between the required accuracy of information and the expected impact (or depth) of a certain decision can be represented by means of figure 2 (see also Braybrooke and Lindblom, 1979).

The desires of actors in private or public agencies with regard to the quality of an information system will very much depend on the nature of the planning problem at hand. In general, one may assume that the claims on an information system will be higher as:

a the frequencies of these choice situations are lower;

$\mathrm{b}$ the range of impacts is larger;

c the number of spillover effects (distributional effects) to other systems is larger;

$\mathrm{d}$ the number of conflicts involved is larger;

e the financial implications are more substantial;

$f$ the time horizon of impacts is longer;

$\mathrm{g}$ the number of decision agencies or actors is larger;

$h$ the outcomes of choices to be made are more uncertain.

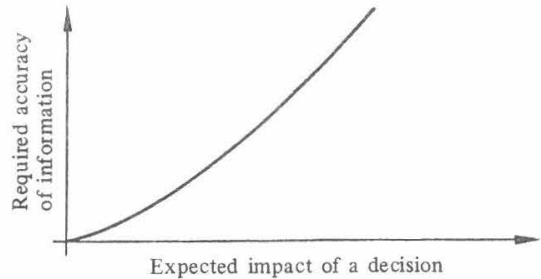

Figure 2. Relationship between information requirement and impact assessment.

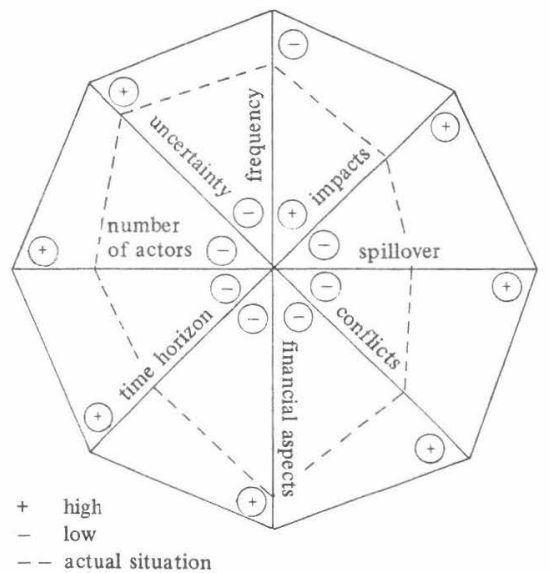

Figure 3. Diagram of demands on information systems caused by the nature of choice problems. The envelope curve reflects the maximum demand and the centre reflects a minimum demand. The actual situation is shown as a dotted line. 
These remarks are illustrated in figure 3, which reflects the demands on information systems as functions of these eight items. The envelope curve reflects the maximum demand, and the interior centre reflects a minimum demand (in case of daily routine decisions, for example).

The above remarks point out once more the existence of difficult trade-offs in policy analysis, decision support, and information provision. These trade-offs emerge from the multipurpose nature of an information system:

the aim of maximum accuracy of the data input (time series, disaggregate survey data, longitudinal data etc);

the aim of maximum quality of the information system (efficiency, flexibility, coherence etc);

the aim of a well-structured choice problem (coordination, conflict management, public participation etc).

These trade-offs can be illustrated by means of the following 'flask model', in which three flasks are connected by means of glass tubes (see figure 4). The three flasks are filled with water, and the three conflictive issues (accuracy of data input, required quality of information system, and complexity of choice problem) are measured on the necks of these flasks. Any change in the water level in one of the flasks has an influence on the level in the remaining flasks, so that a certain trade-off between these conflicting issues is implied by this 'flask model'.

The given quantity of water in the flasks corresponds to a given amount of effort for the three issues at hand. The precise trade-offs between these issues are represented by the shape and the size of each individual flask. In physical terms, a change in the water level in one of the flasks would require a certain external pressure on the water surface. Analogously, in policy terms, more emphasis on one of the three issues will lead to a relaxation of the efforts to be made for the remaining issues. Combined actions (for example, more emphasis both on better data and on higher quality of information systems) are also possible in this framework.

It is easily seen from figure 4 , that a low accuracy of data will either demand a high quality of the information system or will lead to a less organized choice situation.

In conclusion, the aim of designing a good information system is to enhance the efficiency of data use and the effectiveness of policy choices, based on a wellstructured transformation of data into manageable policy information (by using inter alia man-machine interactions, knowledge-based systems, connecting networks, decision support systems, and so forth).

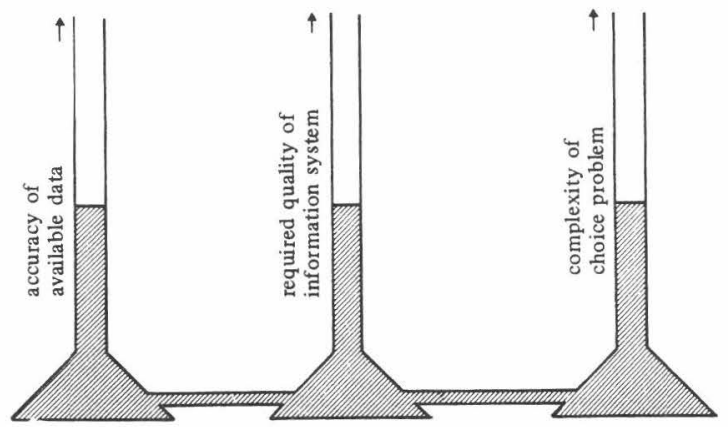

Figure 4. Trade-offs among three items in a choice problem, illustrated by a 'flask model' in which three conflictive issues are measured on the necks of three interconnected flasks filled with water. 


\section{Spatially oriented information systems}

A systematic and coherent insight into the complex pattern and evolution of a spatial system requires the design of an up-to-date, accessible, and comprehensive spatial information-system. Information systems for urban and regional planning should contain structured data on real-world development patterns, their properties (stability, for example) and their mutual links in a spatial context.

Frequently, however, information systems are oriented to the national level or to specific sectors. The geographical dimension of an information system as a decision aid in urban and regional development planning has too often been neglected. Therefore, much more attention is needed for the design and development of information systems reflecting socioeconomic processes so as to arrive at a better representation of spatial systems and a better adaptation to the needs of urban and regional planners (compare Blumenthal, 1969).

Any spatial system can be subdivided into smaller spatial entities (regions, counties, cities, districts, etc). The demarcation principle for spatial subdivisions is not usually unambiguous, as this is codetermined by:

the institutional-administrative structure of the system at hand; the functional-economic interactions and intensiveness of the spatial system; the availability of a spatially oriented data base.

In reality, the spatial demarcation for information systems is often based on a combination of these approaches.

From a system point of view, one may characterize a spatial system by means of nodes and edges. The nodes represent the spatial entities in the system at hand, and the edges represent the various interactions in space; the nodes and edges may be regarded as stocks and flows, respectively. A simple representation of a spatial system is given in figure 5, which reflects both top-down and bottom-up structures, effects of external developments and of policy measures, and horizontal (regional) interdependencies. In this sense, it includes a multilevel, multiactor, and multiobjective planning structure for a spatial system. In particular, the edges indicate that a spatial information system should focus the attention on spatial interactions and spatial patterns.

Given the remarks, the following specific urban or regional elements of a spatially oriented information-system can be mentioned (for instance, see Bowman and Kutscher, 1980; Garnick, 1980; Torene and Goettee, 1980; Willis, 1972):

Integration The information system should attempt to present relevant data for each relevant spatial level and each relevant spatial unit, so as to guarantee both a comparability of data from one region to another and a coordination of various planning activities in different agencies.

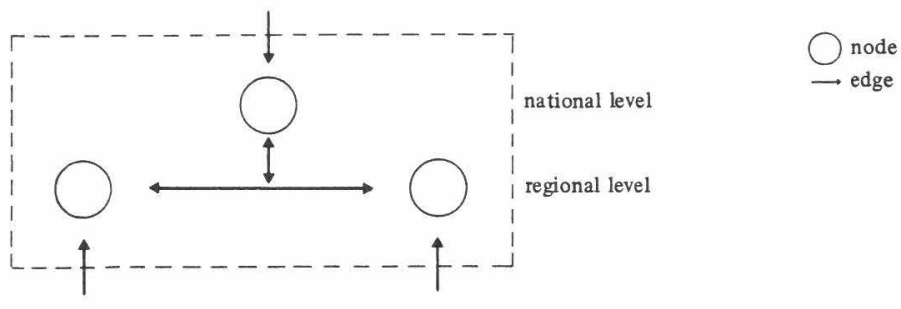

Figure 5. Nodes and edges in a spatial system, illustrating top-down and bottom-up structures between national and regional levels; horizontal interdependencies between regions; and the effects of external developments and policy measures. 
Interregional interaction A regional information-system should reflect the interdependencies within a spatial system by indicating the volumes of interregional commodity flows, migration flows, capital flows, etc.

Spatial spillover effects A spatial information-system should pay attention to spillover effects of a dynamic multiregional open system, including the spatial diffusion patterns through which new technological, social, and economic activities evolve. Specific regional bottlenecks An information system should also indicate whetherand if so, where and why-important regional information is lacking (for instance, the frequent lack of insight into monetary flows between regions).

Multiregional decisionmaking Various decisions affecting a regional economy are made in headquarters of corporate decisionmaking bodies; in addition, flows of income and profits are hard to attribute to a specific region. A spatially oriented informationsystem should try to disentangle the complexity of such a spatial system.

Standardization To make data comparable across regions, the data have to be standardized (for instance, by relating them to the population size or the size of the area). An information system should provide a sound basis for such a standardization and should also indicate the sensitivity of the results for a specific standardization (depending inter alia on the social and demographic structure).

Some interesting examples of urban and regional information-systems designed in the past can be found among others in work by Benjamin, 1976; Elfick, 1979; Guesnier, 1978; Hägerstrand and Kuklinski, 1971; Kuklinski, 1974; Perrin, 1975.

An intriguing problem inherent in any kind of regional information-system appears to be the spatial demarcation of the spatial system (in terms of cities, regions, etc). From an analytical point of view, the spatial demarcation might be based on functional linkages between the spatial entities of the system, although data availability very often hampers the application of this standpoint. From a planning point of view, the spatial demarcation might be based on the existing administrative framework, although data problems may also emerge here (see Hermansen, 1969). This problem is one of the most intriguing problems in designing spatially oriented information-systems and has also led to the current trend to create spatially disaggregated information-systems and models.

In the past, many information systems for regional planning have been developed in close connection with multiregional models. Multiregional models-as an extension of traditional econometric modeling-aim at providing consistent and coherent information on a complex spatial world, so as to identify the main driving forces and the mechanism of a complicated multiregional system (see also Issaev et al, 1982). The aim of coherence and consistency will, in general, lead to a rejection of economic models that do not take into account the openness of a region. Thus, without a consideration of interregional and national-regional links, there is no guarantee of consistency for the spatial system as a whole. Usually, there are various kinds of direct and indirect cross-regional linkages caused by spatiotemporal feedback and contiguity effects, so that regional developments may have a nationwide effect. National or even international developments may also exert significant impacts on a spatial system; this is especially important because such developments may affect the competitive power of regions in a spatial system. For instance, a general national innovation-policy may especially favour areas with large agglomerations. The diversity in an open spatial economic system requires coordination of planning activities on the national and regional level, leading to the necessity of using multiregional economic models in attempts to include regional profiles (sets of relevant policy indicators) in national-regional development planning. 
Let us now make a multiregional planning model focusing on one specific problem area (that is, one specific profile) or on an integrated regional development pattern (including multiple profiles). Then we may assume a general systems framework for a multilevel information-system (see figure 6). This framework includes the input, throughput, and output of a planning model for a spatial system subdivided into cities and regions. The right-hand side of figure 6 reflects the expected results in terms of values of objectives, goal variables, and other relevant endogenous variables. In fact, two main questions may be studied by means of figure 6 .

1 What is the optimum use of a given data input?

2 What is the optimum data input of the information system for a given set of uses? It is clear that the second question is the dual to the first (primal) question. It should also be noted that the versatility for local data is much higher than for regional or national data, since they can be used to build three types of systems models and to assess three different types of profiles.

The structure of figure 6 is based on a top-down pattern. Figure 6 can be used as a tool in designing appropriate spatial information-systems. It should be noted that the output of this information system also displays some interesting features. Local profiles can only be obtained by means of local data and a local model, whereas a national profile can be assessed in many ways, according to the graphs represented in figure 6; for instance, from local data via a multiregional model to a national profile. All such combinations of ways of composing the relevant profiles are certainly worth an in-depth analysis of specific real-world planning problems. It should be noted, that not all data are necessarily observable at the most disaggregate (local) scale. Figure 6 includes essentially the choice of an optimal trajectory for attaining a desired output, given a set of constraints on available data.

This problem is also closely related to the information loss by aggregating from a microlevel to a mesolevel or macrolevel, as this information loss may occur in each of the three stages: data input, models, and final profiles. Similar problems may emerge in attempts to disaggregate existing data into data of a lower spatial level. Such questions are addressed more extensively by Nijkamp, Rietveld, and Rima (1983). Last, the related problem of bottom-up versus top-down approaches may also be addressed in information systems, not only from an institutional point of view, but also from an analytical point of view (see also Nijkamp and Rietveld, 1982).

Data input

Systems model

Output

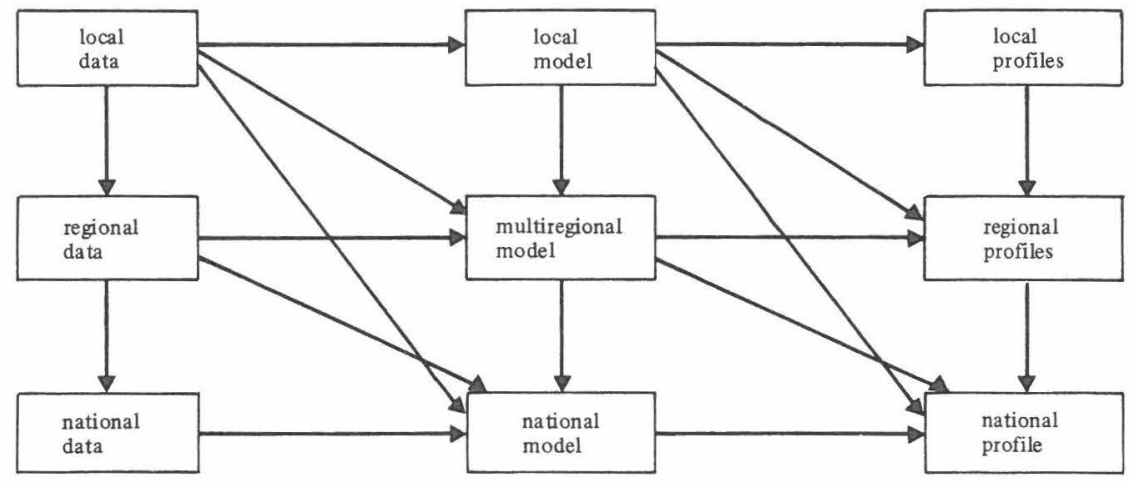

Figure 6. Structure of a multiurban multiregion information-system. 
Information systems for regional planning often suffer from a lack of reliable data. This has of course significant impacts on the reliability of results from (multi)regional planning models. It should be noticed that a less satisfactory specification or performance of regional models is often ascribed to a weak data base. Though it is evident that unreliable data may affect the quality of the results, it is at the same time also true that the structure and econometric aspects of many models presuppose a data base that does not fully exist in reality. In this regard, model users must face and accept a situation of inappropriate information-systems and of gaps in statistical data and must design models that are in closer harmony with the existing information.

In addition to accommodating for lacking data, the possibilities of incorporating qualitative data must be mentioned. Too often, qualitative data are left out of consideration, although such data may contain substantial pieces of information. The recent developments in the area of qualitative (and fuzzy) spatial data analysis may be a meaningful way of employing all relevant available information as well as possible (see also Nijkamp, Leitner, and Wrigley, 1984). Categorical data analysis, generalized loglinear models, ordinal regression analysis, and path analysis (for example, based on partial least squares) are a few examples of modern statistical/econometric tools that are capable of dealing with data measured on a nonmetric scale.

\section{Operational tools for spatially oriented information-systems}

It has already been explained that the aim of information systems is to reduce the uncertainty regarding the expected outcomes of decisions or strategies by means of a systematic data collection and transformation. Several tools for reducing this uncertainty in spatially oriented information-systems have been designed. In the present context, a limited sample of six tools will briefly be discussed.

\subsection{Scenario analysis}

The aim of scenario analysis is to structure a complex long-term choice situation by showing how a set of potential future states can be realized, given the conditions set by the present. Especially in the case of an unstructured decision problem, with uncertain outcomes, scenario analysis may be an appropriate tool. A major difference between scenario analysis and conventional methods of policy analysis is that scenarios contain not only a description of one or more feasible future situations, but also a systematic description of a consistent series of feasible events that reflect the transition from the present state of a system to its future state(s).

Various kinds of scenario may be distinguished, for instance, descriptive and normative, projective and prospective, and trend and contrast scenarios (for more details see Hinloopen and Nijkamp, 1984). In various cases, such scenarios have been used in regional and urban planning, among others in the Netherlands and the United Kingdom.

\subsection{Decision support systems}

Decision support systems take for granted that the quality of a decision and the impact of its implementation are strongly determined by the relevance, the nature, and the quality of the information used. Decision support systems are-unlike management information systems (MIS) - not specially built for daily routine or operating decisions, but especially for nonprogrammed choice problems, strategic decisions, or ad hoc problem-solving activities. Thus, a decision support system may be defined as an automated computer consulting system that primarily aims at actively supporting strategic level decisionmaking in public administration, based on nonmachine interactions and designed to provide relevant information for less structured choice situations. Such a system may be useful in all stages of a planning problem: exploration, definition, design, generation of alternatives, evaluation, and selection. 
For each stage, a decision support system may systematically and coherently pay attention to data collection, data transformation, and data presentation (see also Keen and Scott Morton, 1978; Voogd, 1983a; Young, 1983). A decision support system is particularly suitable for indicating the consequences of intuitive views or subjective considerations in semistructured judgement problems (see Brookes, 1982; Klein and Manteau, 1982). These systems are fairly recent in urban and regional planning, but undoubtedly provide potential for improved decisionmaking.

\subsection{Monitoring}

Monitoring of regional plans is a logical consequence of advocating a procedural model of regional planning (see also Faludi, 1973). Monitoring systems may play an important role in strategic decisionmaking at an urban and regional level. Monitoring is essentially a continuous managerial activity, with a specific view of complex evolving choice or decision problems (see also Batey, 1984; Brown, 1984). Various kinds of monitoring activities may be distinguished, such as implementation monitoring, impact monitoring, and strategic monitoring. Monitoring has proven to be a very useful instrument in case of uncertainty caused by the dynamics of a complex system. Especially in British urban and regional planning practice, it has found a variety of applications.

\subsection{Qualitative evaluation methods}

Qualitative evaluation methods take for granted the qualitative nature of information in multidimensional choice problems. In regard to this, multicriteria analysis had demonstrated its problem-solving capacity in regional and urban planning problems marked by conflicts emerging from the abovementioned uncertainty (see among others Nijkamp, 1980; Nijkamp and Spronk, 1981; Rietveld, 1980; Spronk, 1981; Voogd, 1983b).

Multicriteria analysis is a mode of thinking by which choice problems with conflicting options can be structured and rationalized. Normally, two elements are involved in multicriteria analysis, namely, the assessment of impacts of policy measures for all relevant alternative choice options and the determination of sets of (political or societal) priorities. Very often the impacts and priorities are hard to assess in a cardinal metric. Therefore, qualitative (sometimes also called soft) multicriteria models (based on ordinal or nominal information) may offer a meaningful perspective.

In the case of qualitative multicriteria analysis, various methods may be employed to draw consistent inferences regarding the rankings of alternatives (plans, projects, policies, etc). For more details the reader is referred to papers by Hinloopen et al (1983) and Nijkamp (1982).

\subsection{Early warning systems}

Each planning control process has, among several other difficulties, to deal with a great amount and variety of uncertainties: uncertainties regarding society's values, uncertainties about the effects of decisions, or uncertainties about the environment of the system and its future (compare Friend et al, 1970; 1974). To reduce uncertainties, so-called early warning systems can be used (see Dickey and Watts, 1978). Such systems are characterized by at least four phases, namely, the development of conceptual relationships, collection of data, screening and evaluation of data, and establishing of thresholds.

Early warning systems have been designed for small-scale or business problems, but they are increasingly being used for broader purposes (including urban and regional planning). Especially in the case of process decisions, they may be used as meaningful decision aids in an urban and regional context (see also Voogd and Hamerslag, 1981). 


\subsection{Geocoding}

Geocoding is a specific application of cartographic computer mapping techniques. Various techniques have been developed in this area (see also Tobler, 1979; Steiner, 1980). The main purpose of these techniques is to represent unstructured spatial data in a systematic way, inter alia by characterizing objects by means of their location or position in a network. Geocoding has been developed especially as a tool for a detailed and flexible representation of objects in space at any desired spatial level of detail. For instance, in a geocoding system for an urban housing situation, the following four elements may be distinguished: the cartographic structure, the street structure, the relation structure, and the urban infrastructure (see also van Est and de Vroege, 1984). Geocoding appears to be an operational tool for a representation and retrieval of spatial data, in both a static and a dynamic sense. In addition, it has evolved into an accessible tool for an expert-user dialogue with a great potential for urban and regional planning.

\subsection{Summary}

It should be noted that the above six modern instruments for spatial informationsystems are by no means mutually exclusive. Rather they are complementary, each of them focusing attention on specific attributes of planning problems. For instance, long-run uncertainties may be analyzed by means of scenario analyses or decision support systems; spatially disaggregate problems by means of geocoding and early warning systems; qualitative planning issues by means of decision support systems and qualitative evaluation techniques; procedural aspects of planning by means of monitoring and decision support systems; and bottleneck and threshold analysis by means of early warning systems and scenario methods. The conclusion from this section is that at present a wide variety of tools for information systems exists that can readily be used for a diverse set of urban and regional planning problems.

\section{An international comparison of spatial planning-systems and spatial information-} systems

Regional and urban planning and information systems exhibit a wide variety across various countries, depending on historical, institutional, and political factors. In the framework of a study carried out under the auspices of the International Institute for Applied Systems Analysis (IIASA) in Laxenburg (Austria), a cross-national in-depth comparison of elements and contents of spatial information systems in six different countries was undertaken, Sweden, France, the United States of America, the Netherlands, Czechoslovakia, and Finland.

Clearly, such cross-comparisons are fraught with difficulties because of the differences between countries. The present cross-comparisons have been based on national reports on spatial information-systems for each country written by an expert in this field (for more details see Nijkamp and Rietveld, 1984).

All these national reports were written according to a common standard framework, so that at least a common scope and structure of the cross-national comparisons is guaranteed. Each expert from the country concerned had to provide detailed information on various planning components, linkages between these components, degree of centralization, specific information-systems for each planning component, and so forth. The following components were included in the national reports: housing, transportation, commuting, migration, labour market, environment, and land use.

Two different steps will be described successively here: a comparison of spatial planning-systems and a comparison of spatial information-systems. Each of these systems will be characterized by a set of attributes, and an attempt will be made to describe the position of these systems in the six countries by means of ordinal rankings. 
These rankings may not be interpreted as judgements or evaluations, but only as a way of classifying the various countries.

First, the spatial planning-systems in each of the six countries will be dealt with in a concise manner. The following attributes have been used to characterize the spatial planning-systems at hand:

1 Scope The scope of a planning system refers to the number of planning components included in an integrated spatial planning-system (transportation, housing etc).

2 Intensity The intensity of planning activities reflects not only the number of planning instruments, but also their potential impact (environmental controls, regional employment measures, for example).

3 Centralization Centralization refers here to the vertical linkages between national, regional, and local planning authorities. More centralization means less flexibility and less freedom for regional and local planning activities.

4 Coordination Coordination should be regarded as establishing horizontal links between different planning components. Clearly, coordination may take place at each planning level (national, regional, or local).

5 Process planning Process planning means the presence of feedback mechanisms in planning activities so as to achieve a high degree of flexibility and adjustment. Contrarily, blueprint planning refers to a situation with a clearly defined normative endpoint.

On the basis of a thorough analysis of the successive national reports on spatial planning systems, and after consultation of the successive national experts, the various countries could be ranked in an ordinal sense for each of these five attributes. This was done by carefully analyzing the statements made in each national report regarding each specific attribute. For instance, taking attribute 1 (scope of the spatial planningsystem) as an example, the number of planning components (housing, labour market, land use, etc) in the spatial planning-system of each individual country was assessed. In this respect, the United States of America appeared to have a very low score and France and Czechoslovakia the highest scores. Of course, such an ordinal ranking does not imply any value judgement regarding the quality of the planning system in

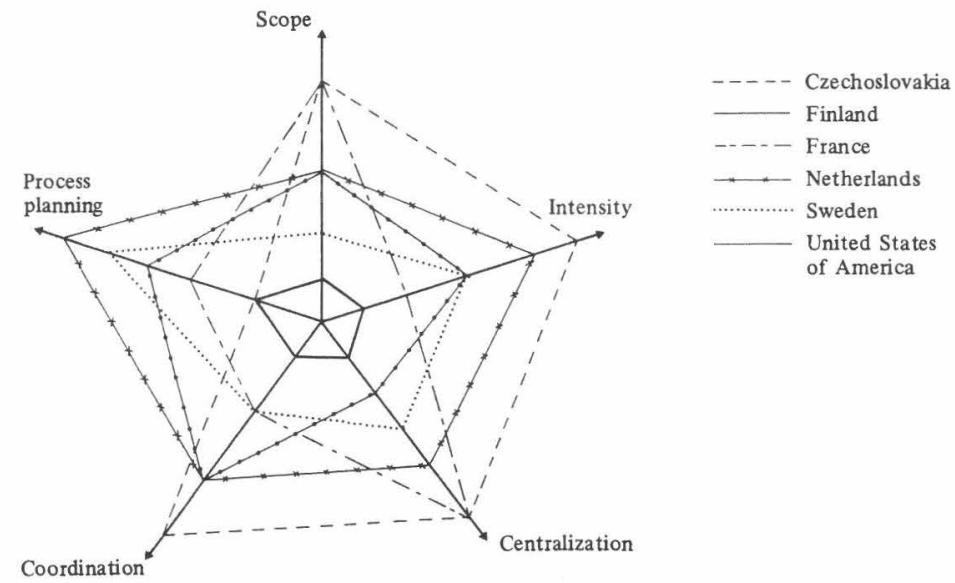

Figure 7. A 'spiderweb' of attributes for spatial planning-systems; the score for each attribute increases outwards from the centre of the web. 
these countries. The results are briefly represented in the 'spiderweb' of figure 7 (for more details see Nijkamp and Rietveld, 1984).

The rankings are defined in such a way that a position near the origin means a low ordinal value of the attribute concerned. The pattern reflected by figure 7 is fairly remarkable. The United States of America clearly has a low ranking of all attributes, whereas Czechoslovakia and the Netherlands apparently have ambitious regional planning-systems. Intermediate positions are taken by Finland, France, and Sweden. Clearly, the positions of the countries also reflect their political systems, and may not be regarded as value judgements regarding the planning systems in these countries.

Next, the spatial information-systems in each of the six countries will briefly be dealt with. The following attributes have been distinguished to characterize the successive information systems.

A Centralization A centralized information-system means that a national agency is responsible for all elements of a spatial (particularly, regional) information-system (including data collection, data storage, and modeling).

B Integration Integration refers here to the extent to which information systems provide an integrated view of the various planning components.

C Role of modeling Modeling activities are regarded here as a way of producing new insights by means of forecasts or impact assessments.

D Regional detail Regional detail means here the level of aggregation at which information systems provide insight into the successive planning components.

E Computerization This aspects deals with the extent to which spatial informationsystems are based on computerization both of inputs for and of outputs from the information systems.

The results of the cross-national comparison of spatial information-systems are summarized in the 'spiderweb' in figure 8. These results exhibit much variation in information systems within each country. Fairly well-developed spatial informationsystems appear to exist in Finland, Sweden, and the Netherlands, but France and the United States of America appear to be marked by less developed information-systems. An intermediate position is taken by Czechoslovakia.

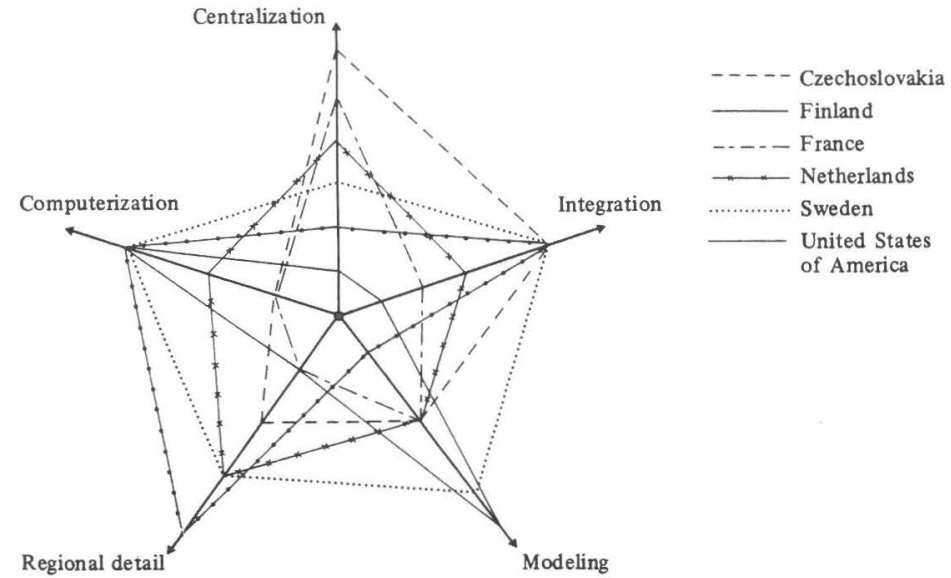

Figure 8. A 'spiderweb' with attributes for spatial information-systems; the score for each attribute increases outwards from the centre of the web. 
The overall conclusion from this cross-national comparison is that there is a remarkable diversity across countries, in terms both of spatial planning-systems and of spatial information-systems. In addition, there is some correspondence between the positions of countries in both 'spiderwebs', but also various exceptions do exist. In conclusion, the area of planning systems and information systems exhibits a very heterogeneous picture.

\section{Conclusion}

Information systems have often been designed for specific purposes: transportation data for transportation policy, housing data for housing market policy, etc. Clearly, there are various rational (institutional and technical) reasons why integration of information systems is hard to achieve in current planning practice. But, a lack of integration means an enormous waste of effort. It would be a significant step forward, if national or regional Bureaus of Statistics were authorized to provide uniform rules for data collection and standard classifications for economic activities, even if it would involve information systems beyond the responsibility of these national and regional bureaus. Experience in technical and medical sciences has demonstrated the power of uniform rules and classifications, and there is no logical reason that would prevent the design of a standard frame of reference for the design of spatially oriented information-systems. This cross-national comparison has demonstrated that there is a serious lack of uniformity in data and information systems, so that cross-national comparisons must be carried out very cautiously.

In addition, the modern computer hardware and software facilities provide a great deal of possibilities for coupling different information-systems. In this respect, public planning agencies may learn extremely meaningful lessons from multiplant and multiregion corporate organizations, which in general, have been able to solve the organizational problems of dealing with enormous diversified data bases. In this regard, the organizational aspects of internal communication within public agencies deserve much more attention. Modern (electronic) networks provide a huge potential for improving acquisition, communication, accessibility, efficiency, monitoring, and public participation in complex public choice problems. Similarly, the software facilities are as important as the information that will be produced by them. In this regard, it is regrettable that computers still play a minor role in modern spatial information-systems.

A major part of this paper has been devoted to the relationship between information systems and regional development planning. It should be noted, however, that information systems are not only a tool in public policy, but may also act as a stimulus for regional and urban development processes. It has been argued by several authors (for instance, Pred, 1973; Thorngren, 1970; Törnqvist, 1970; 1974) that information systems (for example, contact systems, communication flows) may exert a significant impact on industrial location patterns, especially of corporate organizations. Thus, though information systems are of major significance for regional and urban planning, they exert, at the same time, an impact on spatial developments.

In an interesting article, Goddard (1974) has pointed out the impact of corporate organizations (especially when defined in terms of the location of nonmanufacturing functions and their information-flow networks) on regional and urban development processes (through diffusion of technological innovation, polarized development, and regional external economies, for example). Consequently, the management of contact networks through investment in advanced telecommunications, communication audits, and the designation of growth centres based on information exchanging functions, can become an important policy instrument both for organizations and for publicsector agencies concerned with regional development. Thus, the contact pattern of multilocation, multiproduct corporate organizations may exert an important impact 
on regional and urban growth-processes and on the effectiveness of regional and urban policies. Communication audits administered by a public agency may become an appropriate tool in regional and urban policy by highlighting opportunities for firms for alternative locational/organizational arrangements, especially the advantages to be gained through locating different but complementary functions in the same area. Unfortunately, such important issues have not yet been adequately covered by spatial information-systems in various countries.

One of the aspects of analysis which is often absent in regional analysis is a comparative evaluation of regional systems and how they have evolved and changed over time. In our concern for completeness and accuracy, some broad-brush pictures of the regional system, its evolution, and likely future developments tend to be ignored. As a result, the schism often made between the need for policy analysis with partial or simplified models and the use of large-scale models for essentially scientific analysis has become a rather pervasive feature.

Although many countries have amassed an incredibly large collection of regional and interregional information-systems, scientific analysis has tended to focus on the character of the models rather than on the regions which they were representing (compare Batey and Madden, 1981; Hewings, 1983; Massey and Meagan, 1979).

The spatial orientation of many information systems-in general-is not extraordinarily rich. Two important aspects may be distinguished in this respect: the spatial scale and the spatial flows.

In many countries, there is often a lack of consensus between the spatial scale of information systems and that of actual planning problems because of discrepancies between administrative (or legislative) and socioeconomic regional demarcations. In this respect, a closer orientation of information systems towards administrative units is desirable. Given the multilevel pattern of regional decisionmaking, it is in general an appropriate strategy to build up information systems in a bottom-up fashion so as to let them fit flexibly into any desired level of regional planning and policymaking. Computerized information systems (geocoding, for example) may mean an important progress in user-friendly data-processing activities. But it is at the same time clear that many efforts have to be made before complex geographical processes (filtering processes, for example) can be fully described. The current state of the art in this respect is fairly poor.

The second problem concerns the lack of information regarding spatial flows. These flows may be divided into physical and nonphysical flows. In general, there is a reasonable amount of information regarding physical flows (people, commodities, etc). However, as far as nonphysical flows (money flows, knowledge, etc) are concerned, there is a serious lack of knowledge. Consequently, distributional impacts on spatial equity of many public-policy measures are very hard to judge. The lack of money and finance in regional economics and regional planning is especially noteworthy, because in the early history of regional economics some attention was given to an analysis of regional variations in spatial interest-rates (Lösch, 1954) and of spatial flows of funds (Isard, 1960). The usual arguments are that money and financial capital are perfectly mobile, so that it suffices to focus attention only on the real side of the economy. As indicated by Karsch (1982), this view neglects the recent ideas developed in monetarism and neo-Keynesianism and fails to explain why regional unemployment is not a result only of long-term structural change, why capital mobility is not induced by only labour mobility, and why banking and finance tend to agglomerate in a few places. In this regard, spatial information-systems need significant improvement.

An information system should be versatile (that is, accessible for various groups of users and for various objectives). Such a polyvalent nature of information requires a 
specific presentation for each relevant group (for example, planners, model builders, systems analysts, statisticians, data-processing specialists, policymakers, public interest groups). It is a far from easy task to develop the desirable computer software to ensure this flexibility in using information systems for various purposes (including a dialogue between various users).

User-oriented information-systems are necessary to improve the communication between analysts and policymakers and to avoid a 'black box' view of policy analysis and modeling. Modern communication and information technology offer many perspectives in this regard, as analytical tools can be made more accessible to policymakers through desk-top computer terminals and user-friendly software (interactive computer graphics, for example). Recent developments in adaptive information-systems must be applied in regional planning to bridge the gap between information experts and responsible policy agencies (compare Mayer and Greenwood, 1980).

Our current information-society needs rapid access to statistical information. Obstacles in obtaining appropriate data on time-in usable form-may be caused by unavailability of basic data (financial flows data, for example) or underutilization of existing data bases. An important lesson to be drawn from this situation is that more information is also needed on the contents and structure of current information-systems. In the case of lack of data, it has to be emphasized that the widespread availability of computers today also means that users may process statistical data themselves, as is reflected in the current popularity of machine-readable data files. Furthermore, public agencies should be aware of a wide variety of data-finding aids, such as published catalogues, published indexes, and table-finding guides, and computerized cataloguing and query systems (see also Sprehe, 1982). Recent developments in the field of decision support systems and artificial intelligence systems indicate that modern computer technology (especially with regard to data-base management, data retrieved, and data display) offer many new perspectives for adaptive information-systems in a situation of economic dynamics.

The cross-comparison in this paper shows that in the majority of countries regional information-systems are not yet fully developed. The potential use of modern information technology is much higher than its current use. This may be because of expected high costs, lack of insight, institutional rigidities, and lack of coordination. But it should also be realized that a more adequate design and use of modern information-systems for regional planning may lead to much higher social benefits, as then the quality of decisionmaking will no doubt be improved.

Acknowledgement. The author acknowledges the stimulating support given by the IIASA scientific staff.

\section{References}

Batey P W J, 1984, "Information for long-term planning of regional development" in Information Systems for Integrated Regional Planning Eds P Nijkamp, P Rietveld (North-Holland, Amsterdam) pp 63-80

Batey P W J, Madden M, 1981, "Demographic-economic forecasting within an activity-commodity framework: some theoretical considerations and empirical results" Environment and Planning $A$ $131067-1083$

Benjamin B, 1976, "Statistics and research in urban administration and development" International Association for Regional and Urban Statistics, The Hague

Blumenthal S C, 1969 Management Information Systems (Prentice-Hall, Englewood Cliffs, NJ)

Bowman C T, Kutscher R E, 1980, "The labor market data base for multiregional models" in Modeling the Multiregional Economic System Eds F G Adams, N J Glickman (D C Heath, Lexington, MA) pp 57-64

Braybrooke D, Lindblom C E, 1979 A Strategy of Decision (Free Press, New York) 
Brookes C H P, 1982, "Incorporating text-based information within a DSS" in DSS-81 Transactions Proceedings of the 1st International Conference on DSS (University of Georgia Press, Athens, GA) pp 86-107

Brown P J B, 1984, "Monitoring and regional information systems under uncertainty" in Information Systems for Integrated Regional Planning Eds P Nijkamp, P Rietveld (North-Holland, Amsterdam) pp 80-100

Burch J G, Strater F R, Grudnitski G, 1979 Information Systems: Theory and Practice (John Wiley, New York)

Casley D J, Lury D A, 1981 Data Collection in Developing Countries Clarendon Press, London)

Chatterjee L, Nijkamp P (Eds), 1983 Urban and Regional Policy Analysis for Developing Countries (Gower, Aldershot, Hants)

Commission on Geographical Data Sensing and Processing of the International Geographic Union, 1980 Computer Software for Spatial Data Handling International Geographical Union, Ottawa

Dickey J, Watts T, 1978 Analytic Techniques in Urban and Regional Planning (McGraw-Hill, New York)

Elfick M (Ed.), 1979 URPIS Seven The Australian Urban and Regional Information Systems Association, Melbourne

Faludi A, 1973 Planning Theory (Pergamon Press, Oxford)

Friend J K, Jessop W N, Power J M, 1970, "The LOGIMP experiment: a collaborative exercise in the application of a new approach to local planning problems" Information Paper 25, Centre for Environmental Studies, London

Friend J K, Power J M, Yewlett C J L, 1974 Public Planning: The Intercorporate Dimension (Tavistock Publications, Andover, Hants)

Garnick D H, 1980, "The regional statistics system" in Modeling the Multiregional Economic System Eds F G Adams, N J Glickman (D C Heath, Lexington, MA) pp 25-48

Goddard J B, 1974, "Organizational information flows and the urban system" in Issues in the Management of Urban Systems Eds H Swain, R D MacKinnon, International Institute for Applied Systems Analysis, Laxenburg, Austria, pp 180-225

Guesnier B, 1978, "Le système d'information régional" mimeo, Institute of Regional Economics, University of Poitiers, Poitiers, France

Hägerstrand T, Kuklinski A R (Eds), 1971 Information Systems for Regional Development University of Lund, Lund, Sweden

Hermansen T, 1969, "Requirements and provision of information for regional development planning in Sweden" mimeo, United Nations Research Institute for Social Development, Geneva

Hewings G J D, 1983, "Regional and interregional accounting systems for development planning under conditions of limited information" in Urban and Regional Policy Analysis in Developing Countries Eds P Nijkamp, L Chatterjee (Gower, Aldershot, Hants) pp 181-202

Hinloopen E, Nijkamp P, 1984, "Information systems and uncertainty in planning" Information Systems for Integrated Regional Planning Eds P Nijkamp, P Rietveld (North-Holland, Amsterdam) pp 101-120

Hinloopen E, Nijkamp P, Rietveld P, 1983, "Analysis of conflicts and compromises using qualitative data" Regional Science and Urban Economics 13 77-102

Isard W, 1960 Methods of Regional Analysis (MIT Press, Cambridge, MA)

Issaev B, Nijkamp P, Rietveld P, Snickars F (Eds), 1982 Multiregional Economic Modeling: Practice and Prospect (North-Holland, Amsterdam)

Karsch Ch, 1982, "Flow of funds by state for Austria" mimeo, Department of Economics, University of Vienna, Vienna

Keen P G W, Scott Morton M, 1978 Decision Support Systems (Addison-Wesley, Reading, MA)

Klein M, Manteau A, 1982 "OPTRANS: a tool for implementation of decision support systems" in Proceedings Working Conference on Processes and Tools for Decision Support International Institute for Applied Systems Analysis, Laxenburg, Austria

Kuklinski A R (Ed.), 1974 Regional Information and Regional Planning (Mouton, The Hague)

Leontief W W, 1982, "The international use of input -output analysis" in The International Use of Input-Output Analysis Ed. R Stäglin (Vandenhoeck and Ruprecht, Göttingen) pp 19-26

Lösch A, 1954 The Economics of Location (Yale University Press, New Haven, CT)

Massey D, Meagan R, 1979 Progress in Planning 10. The Geography of Industrial Reorganisation (Pergamon Press, Oxford)

Mayer R R, Greenwood E, 1980 The Design of Social Policy Research (Prentice-Hall, Englewood Cliffs, NJ)

Nijkamp P, 1979 Multidimensional Spatial Data and Decision Analysis (John Wiley, Chichester, Sussex)

Nijkamp P, 1980 Environmental Policy Analysis (John Wiley, Chichester, Sussex) 
Nijkamp P, 1982, "Soft multicriteria analysis as a tool in urban land-use planning" Environment and Planning $B 9$ 197-208

Nijkamp P, Leitner H, Wrigley N (Eds), 1984 Measuring the Unmeasurable (Martinus Nijhoff, The Hague)

Nijkamp P, Rietveld P, 1982, "Structure analysis of spatial systems" in Multiregional Economic Modeling: Practice and Prospect Eds B Issaev, P Nijkamp, P Rietveld, F Snickars (North-Holland, Amsterdam) pp 35-48

Nijkamp P, Rietveld P (Eds), 1984 Information Systems for Integrated Regional Planning (NorthHolland, Amsterdam)

Nijkamp P, Rietveld P, Rima A, 1984, "Information content of data from different spatial aggregation levels" in Information Systems for Integrated Regional Planning Eds P Nijkamp, P Rietveld (North-Holland, Amsterdam) pp 215-230

Nijkamp P, Spronk J, 1981 Multicriteria Analysis: Operational Methods (Gower, Aldershot, Hants)

Perrin J C, 1975 Le Développement Régional (Presses Universitaires de France, Paris)

Pred A, 1973 Urban Growth and the Circulation of Information (Harvard University Press, Cambridge, MA)

Rietveld P, 1980 Multiple Objective Decision Making in Regional Planning (North-Holland, Amsterdam)

Rittel H, 1982, "Structure and usefulness of planning information systems" in Human and Energy Factors in Urban Planning Eds P Laconte, J Gibson, A Rapoport (Martinus Nijhoff, The Hague) pp 53-64

Roy B, 1981, "A multicriteria analysis for trichotomic segmentation problems" in Multiple Criteria Analysis Eds P Nijkamp, J Spronk (Gower, Aldershot, Hants) pp 245-258

Sowell T, 1980 Knowledge and Decision (Basic Books, New York)

Sprehe J T, 1982, "A federal policy for improving data access and user services" Statistical Reporter March, pp 323-341

Spronk J, 1981 Interactive Multiple Goal Programming for Capital Budgeting and Financial Planning (Martinus Nijhoff, The Hague)

Steiner D, 1980, “A minicomputer-based geographical data planning system" Map Data Processing Eds C H Freemand, G Pieroni (Academic Press, New York) pp 1-25

Thorngren B, 1970, "How do contact systems affect regional development?" Environment and Planning 2 409-427

Tobler W R, 1979, "A transformational view of cartography" The American Cartographer 6 101-106

Torene R, Goettee D, 1980, "Towards a general purpose economic data base" in Modeling the Multiregional Economic System Eds F C Adams, N J Glickman (D C Heath, Lexington, MA) pp $65-72$

Törnqvist G, 1970 Contact Systems and Regional Development Lund Studies in Geography, Series B, number 35 (Gleerup, Lund)

Törnqvist G, 1974, "Spatial organization of activity spheres" in Issues in the Management of Urban Systems Eds H Swain, R D MacKinnon, International Institute for Applied Systems Analysis, Laxenburg, Austria, pp 226-265

Van Est J, de Vroege F, 1984,"Disaggregate spatial information systems" in Information Systems for Integrated Regional Planning Eds P Nijkamp, P Rietveld (North-Holland, Amsterdam) pp 250-262

Voogd J H, 1983a, "Decision support systems voor overheidsplanning" mimeo, Department of Civil Engineering, Delft University of Technology, Delft, The Netherlands

Voogd J H, 1983b Multicriteria Evaluation for Urban and Regional Planning (Pion, London)

Voogd J H, Hamerslag R, 1981, "Early warning systems for process keeping" in Nieuwe Tendensen in de Vervoersplanologie Eds J van Est and others (Colloquium Vervoersplanologisch Speurwerk, The Hague) pp 511-528

Wilbanks Th J, Lee R, 1984, "Policy analysis in theory and practice" in The Regional Consequences of Large Scale Energy Development Eds B Johansson, T R Lakshmanan (North-Holland, Amsterdam) forthcoming

Willis J, 1972, "Design issues for urban and regional information systems" Centre for Environmental Studies, London

Young L F, 1983, "Computer support for creative decision-making: right-brained DSS" in Processes and Tools for Decision Support Ed. H H Sol (North-Holland, Amsterdam) pp 47-64 